\title{
An experiment to measure raindrop collection efficiencies: influence of rear capture
}

\author{
A. Quérel ${ }^{1,2, *}$, P. Lemaitre ${ }^{1}$, M. Monier ${ }^{2,3}$, E. Porcheron ${ }^{1}$, A. I. Flossmann ${ }^{2,3}$, and M. Hervo ${ }^{2,3}$ \\ ${ }^{1}$ Institut de Radioprotection et de Sûreté Nucléaire (IRSN), PSN-RES, SCA, LECEV, Gif-sur-Yvette, France \\ ${ }^{2}$ Clermont Université, Université Blaise Pascal, Laboratoire de Météorologie Physique, Clermont-Ferrand, France \\ ${ }^{3}$ CNRS, INSU, UMR6016, LaMP, Aubière, France \\ * now at: CEREA, Centre d'Enseignement et de Recherche en Environnement Atmosphérique, Joint Laboratory of Ecole des \\ Ponts ParisTech/EDF R\&D, Université Paris-Est, Marne-la-Vallée, France \\ Correspondence to: P. Lemaitre (pascal.lemaitre@irsn.fr)
}

Received: 21 October 2013 - Published in Atmos. Meas. Tech. Discuss.: 22 January 2014

Revised: 1 April 2014 - Accepted: 1 April 2014 - Published: 19 May 2014

\begin{abstract}
In the case of severe accident with loss of containment in a nuclear plant, radionuclides are released into the atmosphere in the form of both gases and aerosol particles (Baklanov and Sørensen, 2001). The analysis of radioactive aerosol scavenged by rain after the Chernobyl accident highlights certain differences between the modelling studies and the environmental measurements. Part of these discrepancies can probably be attributed to uncertainties in the efficiencies used to calculate aerosol particle collection by raindrops, particularly drops with a diameter larger than one millimetre. In order to address the issue of these uncertainties, an experimental study was performed to close the gaps still existing for this key microphysical parameter. In this paper, attention is first focused on the efficiency with which aerosol particles in the accumulation mode are collected by raindrops with a diameter of $2 \mathrm{~mm}$. The collection efficiencies measured for aerosol particle in the sub-micron range are quantitatively consistent with previous theoretical model developed by Beard (1974) and thus highlight the major role of rear capture in the submicron range.
\end{abstract}

\section{Introduction}

Aerosol particles are an important component of the atmosphere. They significantly contribute to the Earth's energy budget, by directly interacting with radiation as well as serving as nuclei during cloud formation. The second effect, also called the indirect effect, is currently the main source of uncertainties in forecasting the future climate. In addition, particulate matter and its physical properties (size of particles, affinity with water, etc.) are key parameters in defining air composition and quality, and are of great importance in terms of health hazard.

Aerosol particles originate in many ways. The primary natural sources are sea spray, wind-driven dust, volcanic eruptions, and a secondary source is the condensation from the vapour phase. The size of these particles greatly varies and ranges from one nanometre to several hundred microns. One major origin of particulate matter is from anthropogenic sources. Of all man-made pollution, one type is particularly dangerous to human health and the quality of the environment: the radioactive releases from a nuclear accident.

Just like all other particles, once emitted, radioactive particles undergo physical processes that drastically change their size distribution during their transport in the atmosphere. Small particles disappear by coagulation and large particles are large enough to sediment to the ground. However, there is a significant range of particle sizes in the atmosphere, mostly unaffected by these removal mechanisms, called the accumulation mode (Whitby, 1973). This mode is made up of aerosol particles with diameters between $0.1 \mu \mathrm{m}$ and $1 \mu \mathrm{m}$. These particles may remain in the atmosphere for several months (Pruppacher and Klett, 1997), and this particulate matter can be transported over long distances, crossing the continents. However, even this particulate matter does not accumulate endlessly in the atmosphere, as clouds and their precipitation scavenge them from the atmosphere. Particles of the 
accumulation mode will be taken out of the atmosphere by what is called "wet removal". This includes many processes such as their activation in cloud droplets or ice crystals, and their collection by falling hydrometeors either inside or below the clouds during precipitation.

Different physical processes need to be taken into account to understand how the atmospheric concentration of particulate matter changes with size in the accumulation mode, how particles are removed, and how they can contaminate the ground. Certain aspects of these processes are still not well understood. While in-cloud processes and their interaction with aerosol particles have been studied extensively (e.g. Flossmann and Wobrock, 2010), the processes taking place below the cloud in the precipitation region have received less attention. In this study, however, we will focus on the below-cloud removal of particles by precipitation, the so-called wash-out process. Volken and Schumann (1993) and Laakso et al. (2003) showed that considerable differences appeared between their environmental scavenging coefficients and those calculated using the model described by Slinn (1977). A crucial parameter for these calculations is the collection efficiency that appears in the calculation of particle collection by a falling hydrometeor, i.e. how many particles are collected by a falling drop compared to the particles in the volume that the drop has swept. Following streamlines around the drop prevents particles from being caught. For small ones, Brownian motion allows them to leave the streamlines and, for large particles, their inertia induces their impaction or interception by the drop. In the intermediate size range, collection efficiencies are low and these minimum values are known as the Greenfield gap (Greenfield, 1957), contributing to the creation of an accumulation mode. Scavenging models similar to the Slinn (1977) model use parameterisation to account for Brownian motion, inertial impaction and interception. Several hypotheses have been put forward to explain why these modelled scavenging coefficients still differ from measurements. Skibin et al. (1986) emphasised the effect of downdraft or updraft on the variation of aerosol concentrations. Davenport and Peters (1978) and Flossmann (1991) highlighted the influence of aerosol hygroscopicity on their washout. Wang et al. (1978) discussed the influence of electric effects that can increase the collection efficiencies up to an order of magnitude in the Greenfield gap. Finally, an additional uncertainty, according to Wang and Pruppacher (1977), involves the lack of knowledge on the collection efficiencies of large raindrops (with a diameter larger than $1 \mathrm{~mm}$ ). First, large drops oscillate during their fall (Szakáll et al., 2009, 2010); additionally, eddies develop downstream of large drops allowing small aerosol to be embedded in that secondary circulation and be captured at the rear of the drops or shed with the eddies (Beard, 1974). These two phenomena are the reason why modelling of the flow around a large drop is not feasible and that those collection efficiencies cannot be theoretically determined. Experiments have provided efficiencies for this size range, e.g. Kerker and Hampl (1974), Grover et al. (1977); Wang and Pruppacher (1977); Lai et al. (1978); Pranesha and Kamra (1996); Vohl et al. (1999). However, these measurements only provide a patchy inside on the drop/particle collection process, as in particular for particles larger than $1 \mu \mathrm{m}$ and drops between 0.2 and $3 \mathrm{~mm}$ diameter almost no observations exist (see Fig. 1 of Quérel et al., 2014).

For the current study, thus, we designed an experiment to lower the collection efficiency uncertainties in these unexplored regions. In the next section we present a theoretical study to assess which size range of falling raindrops has the largest impact for below-cloud scavenging and needs, thus, the most accurate values. Then we present the design of the experimental facility. Measurements and uncertainties are discussed in the result section before the final conclusion.

\section{Design of the experiment to determine collection efficiency}

DESCAM (DEtailed SCavenging Model) is a bin-resolved cloud microphysics model (see Flossmann and Wobrock, 2010, Flossmann, 1998, or Quérel et al., 2014, for details). It follows at each grid point number size distributions for liquid droplets, ice crystals and aerosol particles in the ambient air, as well the aerosol mass taken up into the drops and ice crystals. This model is, thus, designed to study aerosol particle scavenging. For the current study, DESCAM has been adapted to be used in a vertical column to identify for which raindrop sizes an accurate value for collection efficiencies by raindrops is most important. Sensitivity studies have been performed for precipitation, prescribed by a raindrop size distribution according to Marshall and Palmer (1948), falling through a kilometre of atmosphere loaded with aerosol particles log-normally distributed in size according to the continental case of Jaenicke (1988) (see also Quérel et al., 2014). The temperature profile of the atmosphere is assumed to result from an adiabatic cooling of rising air, with a surface temperature of $20^{\circ} \mathrm{C}$. The relative humidity (RH) is set to $70 \%$ throughout the entire layer. The only microphysical process considered for this study is the scavenging of aerosol particles, while the collection efficiencies used are described in Flossmann (1986). Figure 1 shows the raindrop mass distribution reaching the ground, for one of these tests (rainfall rate of $10 \mathrm{~mm} \mathrm{~h}^{-1}$ at the cloud base), as well as the mass of particulate matter taken up within the raindrops. In Fig. 1, we note that while the $1 \mathrm{~mm}$ diameter drops contribute the most to the water mass reaching the ground, the $2 \mathrm{~mm}$ raindrops are the ones that contain the most aerosol particle material. From the compilation of all sensitivity cases with different rainfall rates, we concluded that droplets of 2-3 mm diameter are essential for deposition of the maximum particulate matter. Uncertainties in the collection efficiencies are, thus, likely to have the largest impacts in these size regions. 


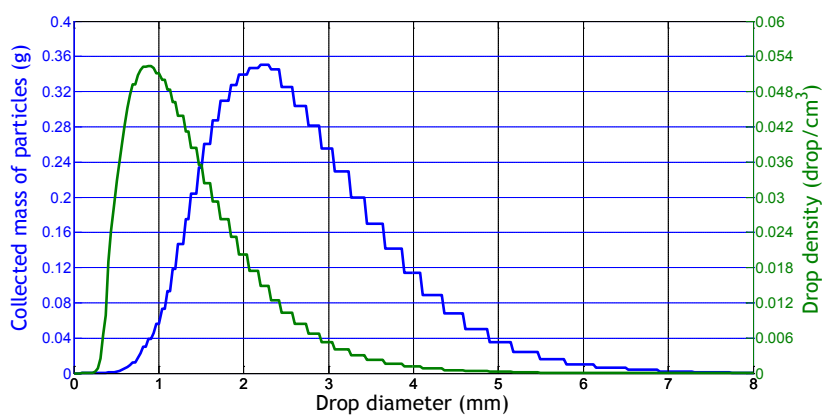

Figure 1. Collected mass of particles and drop density as a function of the drop diameter (using DESCAM).

However, as was mentioned above, in these size ranges almost no measurements have been reported in the literature.

Consequently, this study is dedicated to measuring the collection efficiencies of raindrops with a diameter larger than $2 \mathrm{~mm}$, for aerosol particles in a wide size range, representing the atmospheric particles the most affected by washout in terms of mass (Hobbs, 1993).

The collection efficiency $E\left(d_{\mathrm{AP}}, D_{\mathrm{d}}, \mathrm{RH}\right)$ is conventionally defined as the ratio between the actual cross section of the drop (area through which an aerosol particle must enter the trajectory of the drop) and the geometrical collision cross section of a drop of the same diameter. This is equivalent to defining the collection efficiency as the ratio of the mass of aerosol particles collected by the drop during its fall to the mass of aerosol particles in the volume geometrically swept out by a drop of the same diameter:

$E\left(d_{\mathrm{AP}}, D_{\mathrm{d}}, \mathrm{RH}\right)=\frac{m_{\mathrm{AP}, \text { collected }}\left(d_{\mathrm{AP}}\right)}{m_{\mathrm{AP}, \text { swept }}\left(d_{\mathrm{AP}}\right)}$.

This efficiency is a function of the diameter of the falling drop $\left(D_{\mathrm{d}}\right)$, the diameter of the aerosol particles $\left(d_{\mathrm{AP}}\right)$ and the relative humidity $(\mathrm{RH})$, since phoretic effects are known to play an important role (Wang and Pruppacher, 1977) due to the phoretic forces. Therefore, we aim to reproduce the fall of hydrometeors in the atmosphere and to accurately ascertain the mass of aerosol particles encountered during their path and the mass of particles they collected to determine values of the collection efficiencies.

For this purpose, we have built an experimental facility at IRSN called BERGAME (French acronym for facility to study aerosol scavenging and measure the collection efficiency). This experimental setup is composed of three parts (Fig. 2): a drop generator, a free-fall shaft and an aerosol chamber. The generator is designed to produce a population of millimetre-sized drops with a monodisperse size distribution as close as possible. The free-fall shaft is required to allow the drops to reach their terminal velocity, oscillate and obtain a shape similar to atmospheric raindrops. The collection will then occur in the aerosol chamber in which aerosol particle concentration and the volume swept by the drop are

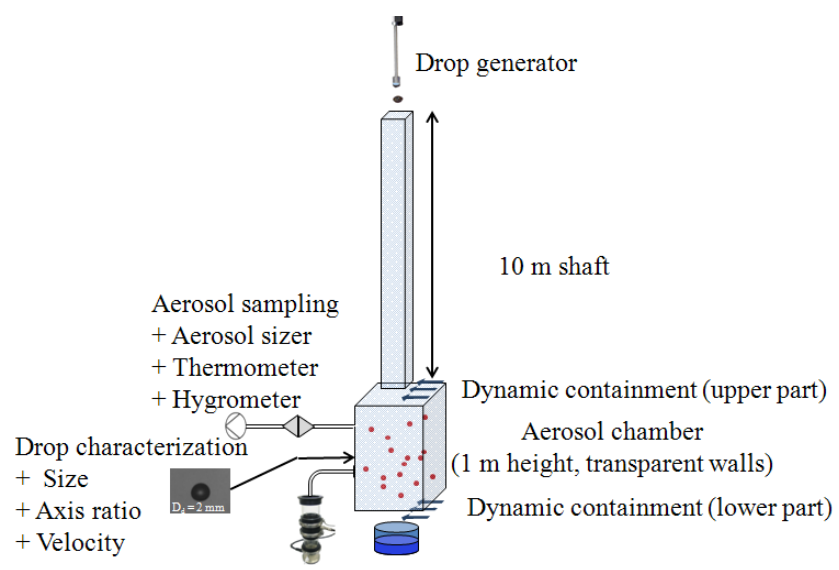

Figure 2. BERGAME setup.

known. To determine the collection efficiency as precisely as possible, concentrations of aerosol both in suspension in the aerosol chamber as well as collected by the drops are measured in mass quantities. The three parts of the facility are described below, and details can be found in Quérel (2012).

\subsection{Drop generator}

The BERGAME drop generator was developed following Lai et al. (1978). It consists of a $30 \mathrm{~cm}$ high vertical tube with a $5 \mathrm{~cm}$ internal diameter. It is equipped with a hypodermic needle at its base and overflows at different heights. This cylinder is fed at constant water flow rate. Thus, the water height inside the cylinder remains constant and the injection pressure inside the needle remains very stable. Therefore, the generator can produce drop after drop with a diameter monodispersedly distributed ranging from $2 \mathrm{~mm}$ to $4 \mathrm{~mm}$ at a stable frequency. To avoid any electric charging of the drop, the generator is grounded. In this study, we focus on drops with a diameter between 2 and $2.6 \mathrm{~mm}$ in diameter.

Both drop diameters and axis ratios of each drop crossing the BERGAME aerosol chamber are directly measured inside the chamber by processing the shadow images of the drop. The drop velocity of each drop is also directly measured inside the aerosol chamber. This measurement is performed by taking a second picture of the shadow of the same drop with a controlled time between these two images. The drop velocity is finally deduced from the ratio between the displacement of the centre drop on the two images and the time between these two images. Unfortunately, the experimental precision of the velocity measurement is low, which explains the significant uncertainties of the velocities presented in Table 1. 


\subsection{Free-fall shaft}

The free-fall shaft is ten metres high and has a square cross section of $0.45 \times 0.45 \mathrm{~m}^{2}$. According to Wang and Pruppacher (1977), it is tall enough for drops with a diameter of around $2 \mathrm{~mm}$ to reach $99 \%$ of their terminal velocity. This shaft is equipped with windows at three levels in order to enable the probing of inside airflows. In this way, the use of a Particle Imaging Velocity technique (PIV, Quérel, 2012) verified that no convective flow occurred inside the shaft. Relative humidity within the shaft is monitored but not controlled. To account for any evaporation during the fall, measurements of the drop size are performed after the fall shaft, directly inside the aerosol chamber.

\subsection{Aerosol chamber}

The aerosol chamber is a stainless steel rectangular cube of $1 \mathrm{~m}$ height $(H$, in Eq. 5) and with a cross section of $0.8 \times 0.8 \mathrm{~m}^{2}$. The chamber is equipped with two apertures: an inlet at the top to allow the drops, coming from the freefall shaft, to fall through the chamber; an outlet at the bottom to allow the collection of the drops after their path through the chamber. Dynamic containment systems (Mocho, 1996) ensure the non-contamination of the shaft and the laboratory with aerosol particles.

The in situ characterisation of the drops during their fall inside the chamber is performed through three existing windows, allowing non-intrusive measurements by optical techniques. The shadowgraphy technique provides the distribution and axis ratio of drops, and the PIV technique gives drop velocity. The complete optical setup is detailed by Quérel (2012). Figure 3 presents the axis ratio distribution measured in the BERGAME aerosol chamber for drops with a diameter of $2 \mathrm{~mm}$.

Table 1 presents the mean and standard deviations of drop velocities $\left(V_{\mathrm{d}}\right)$ and axis ratios measured in the aerosol chamber, compared with the Beard (1976) model for terminal velocity $\left(V_{\infty}\right)$ and the Beard and Chuang (1987) model for axis ratio. These models have been supported by both wind tunnel measurements (Szakáll et al., 2009; Thurai et al., 2009) and in situ environmental measurements (Bringi et al., 2003).

In Table 1 the drop Reynolds number is calculated using Eq. (2) in which $v_{\text {air }}$ is the kinematic viscosity of the gas around the $\operatorname{drop}\left(\mathrm{m}^{2} \mathrm{~s}^{-1}\right)$ :

$R e=\frac{V_{\mathrm{d}} D_{\mathrm{d}}}{v_{\mathrm{air}}}$.

The agreement of these measurements with the literature models ensures the representativeness of the BERGAME setup, in the drop size range investigated. However, beyond the drop diameter size of $2.7 \mathrm{~mm}$, the velocity allowed by this shaft is no more satisfying.

Moreover, this proves that the dynamic containment we added to avoid contamination of the shaft with aerosol
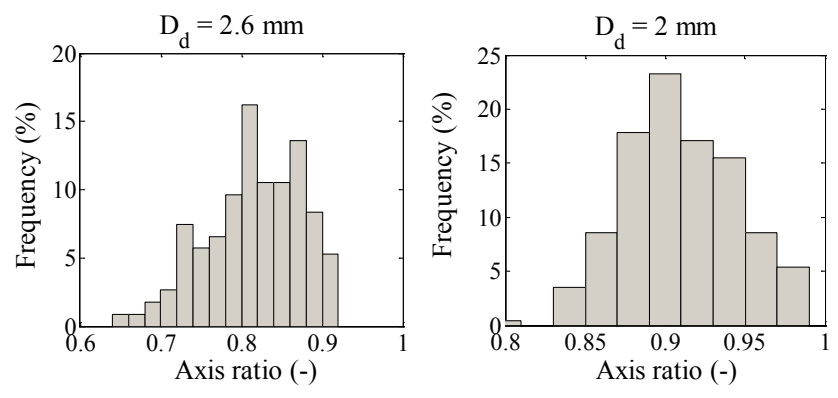

Figure 3. Distribution of axis ratio of drops measured in the BERGAME aerosol chamber over a sample of 200 drops.

particles does not disturb the drops in terms of velocity and axis ratio.

Temperature and relative humidity inside the chamber are monitored continuously during the experiments using a thermocouple and a capacitive hygrometer. To measure the mass density of aerosol particles inside the chamber, a known volume is pumped through a HEPA filter, and analysed with a fluorimetric method. Finally, the Particle Size Distribution (PSD) is measured inside the chamber in terms of aerodynamic diameters, by simultaneously using an Electrical Low Pressure Impactor (ELPI, Marjamaki et al., 2000) and an Aerodynamic Particle Sizer (APS, TSI-3321). These two particle sizers are used for their complementary size ranges $(500 \mathrm{~nm}-20 \mu \mathrm{m}$ for the APS, $7 \mathrm{~nm}-10 \mu \mathrm{m}$ for the ELPI). The aerosol chamber is furnished with monodisperse aerosol particles generated with ultrasonic nebulisers.

\subsection{Aerosol generator and particle characterisation}

The aerosol particles studied in this work consist of pure fluorescein $\left(\mathrm{C}_{10} \mathrm{H}_{10} \mathrm{Na}_{2} \mathrm{O}_{5}\right)$, successively generated with the help of two ultrasonic nebulisers (Sinaptec GA 2400, GA 500, Bemer and Tierce, 1996) producing monodisperse aerosol particles between $300 \mathrm{~nm}$ and $4 \mu \mathrm{m}$. These aerosol particles are selected because of their very important fluorescence properties which are essential for the spectroscopy technique used later to measure their concentrations inside the drops. The principle of this atomiser is simple. Ultrasounds, produced by a piezoelectric ceramic, nebulise a solution of fluorescein (dissolved in distilled water at various concentrations) and thus generate droplets. These droplets are dried and the produced aerosol particles are carried in the aerosol chamber by a monitored airflow.

The diameters of the particles in the aerosol chamber are measured with both APS and ELPI in terms of their aerodynamic diameter $\left(d_{\mathrm{ae}}\right)$. This aerodynamic diameter is then converted into a physical diameter $d_{\mathrm{ap}}$ using Eq. (3) (Baron and Willeke, 2001). According to Motzkus (2007) the shape factor of fluorescein aerosol particles is close to unity, thus the physical diameter $d_{\text {ap }}$ also corresponds to the equivalent 
Table 1. Comparison between drop velocities and axis ratios measured in the BERGAME aerosol chamber with models to determine drop velocity (Beard, 1976) and axis ratio at equilibrium (Beard and Chuang, 1987).

\begin{tabular}{llrlrr}
\hline $\begin{array}{l}\text { Drop } \\
\text { diameter }\end{array}$ & $\begin{array}{l}\text { Drop } \\
\text { velocity }\end{array}$ & $\begin{array}{r}\text { Reynolds } \\
\text { number }\end{array}$ & $\begin{array}{l}\text { Axis } \\
\text { ratio }\end{array}$ & $\begin{array}{r}\text { Terminal velocity } \\
\text { (Beard model, } \\
1976)\end{array}$ & $\begin{array}{r}\text { Equilibrium axis ratio } \\
\text { (Beard and Chuang } \\
\text { model, 1987) }\end{array}$ \\
\hline $2.0 \pm 0.1 \mathrm{~mm}$ & $6.2 \pm 1.1 \mathrm{~m} \mathrm{~s}^{-1}$ & 818 & $0.93 \pm 0.04$ & $6.4 \mathrm{~m} \mathrm{~s}^{-1}$ & 0.93 \\
$2.6 \pm 0.1 \mathrm{~mm}$ & $7.4 \pm 0.9 \mathrm{~m} \mathrm{~s}^{-1}$ & 1314 & $0.87 \pm 0.09$ & $7.5 \mathrm{~m} \mathrm{~s}^{-1}$ & 0.87 \\
\hline
\end{tabular}

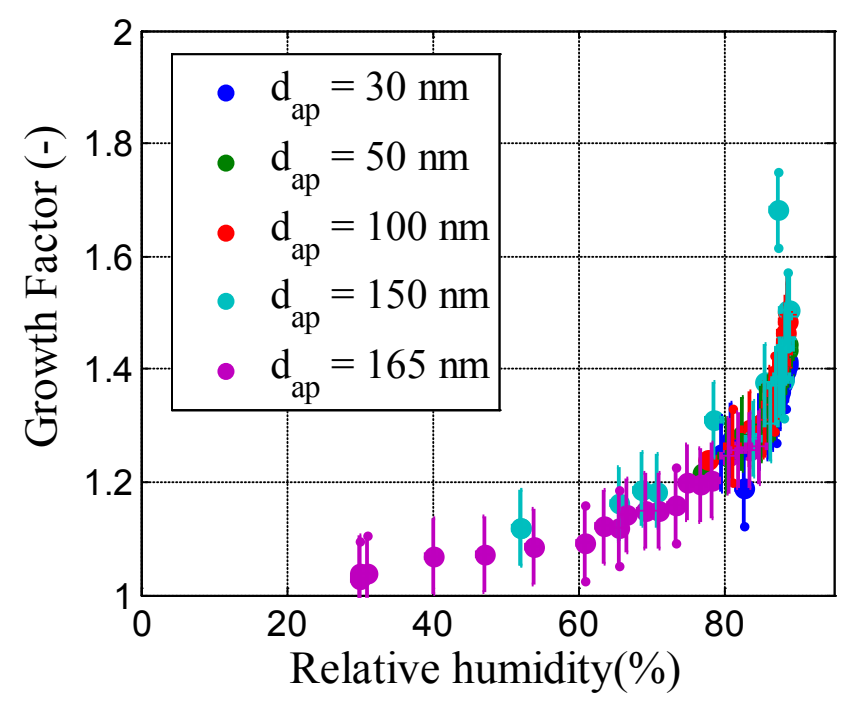

Figure 4. Growth factor (GF) of fluorescein aerosol particles measured using an HTDMA (according to Villani et al., 2008, the RH and GF uncertainties are respectively less than $1 \%$ and 0.07 ).

volume diameter:

$d_{\mathrm{ap}}=d_{\mathrm{ae}} \sqrt{\frac{C_{\mathrm{c}, d_{\mathrm{ae}}}}{C_{\mathrm{c}, d_{\mathrm{ap}}}}\left(\frac{\rho_{0}}{\rho_{\mathrm{p}}}\right)}$,

where $\rho_{0}$ and $\rho_{\mathrm{p}}$ are respectively the standard density of liquid water $\left(1000 \mathrm{~kg} \mathrm{~m}^{-3}\right)$ and aerosol particles, and $C_{\mathrm{c}}$ is the Cunningham slip correction factor (Hinds, 1982). The ratio $\left(\frac{C_{\mathrm{c}, d_{\mathrm{ae}}}}{C_{\mathrm{c}, d_{\mathrm{ap}}}}\right)$ is considered equal to 1 . The density of the aerosol particles is determined with the help of

$\rho_{\mathrm{p}}=\frac{\rho_{\mathrm{C}_{10} \mathrm{H}_{10} \mathrm{Na}_{2} \mathrm{O}_{5}}+\rho_{\text {Water }}\left(\mathrm{GF}^{3}-1\right)}{\mathrm{GF}^{3}}$,

where the growth factor (GF) of fluorescein aerosol particles is measured with a Hygroscopic Tandem Differential Mobility Analyser (HTDMA, Villani et al., 2008). The measured growth factors as a function of relative humidity are presented in Fig. 4.

\subsection{Experimental procedure}

Each experiment starts by flushing the aerosol chamber with dry filtered air. Then the drop generator is set to the desired drop size ( 2 or $2.6 \mathrm{~mm}$ in this set of experiments). The drops generated are characterised inside the aerosol chamber after their acceleration inside the free-fall shaft (Fig. 3 and Table 1). This characterisation consists of measuring the droplet diameters, axis ratios, and velocities inside the aerosol chamber.

Then, the aerosol chamber is filled with fluorescein aerosol particles, and their size is measured continuously with both APS and ELPI. Figure 5 presents a characteristic aerosol particle size distribution measured in the aerosol chamber by means of the APS; the geometric standard deviation of the aerosol particle size distribution is of the order of 1.3. Finally, we start the aerosol sampling on the HEPA filter at a flow rate of $1 \mathrm{~L} \mathrm{~min}^{-1}$ and the drop collection. For each measurement, a sample of $1.2 \mathrm{~g}$ of drops is collected (300 drops with a diameter of $2 \mathrm{~mm}$ ). The mass of fluorescein collected on the filter and by the drops are both measured with fluorescence spectroscopy, making it possible to determine respectively the mass concentration of fluorescein particles in suspension inside the aerosol chamber ([fluoAC]), and the concentration of fluorescein inside the drops ([fluoDrop]). Since temperature and relative humidity are both monitored inside the aerosol chamber, the combination of all these measurements enables us to calculate the collection efficiency:

$E\left(d_{\mathrm{AP}}, D_{\mathrm{d}}, \mathrm{RH}\right)=\frac{2 D_{\mathrm{d}}}{3 H} \frac{[\text { fluoDrop }]}{[\text { fluoAC }]}$.

This entire procedure was conducted 399 times and provided measurements of the collection efficiencies of aerosol particles between $0.3 \mu \mathrm{m}$ and $3.5 \mu \mathrm{m}$ in diameter by drops between 2 and $2.6 \mathrm{~mm}$ in diameter.

\section{Preventing sources of error and assessment of uncertainties}

A careful assessment of all uncertainties revealed that the main source of error results from a potential fluorescein contamination of any item in the BERGAME setup (free-fall shaft, aerosol chamber or laboratory). This contamination is assessed before each experiment. A sample of 300 drops is collected just above the aerosol chamber after their acceleration in the free fall shaft. This sample is analysed by fluorescence spectroscopy. If the fluorescein mass concentration 


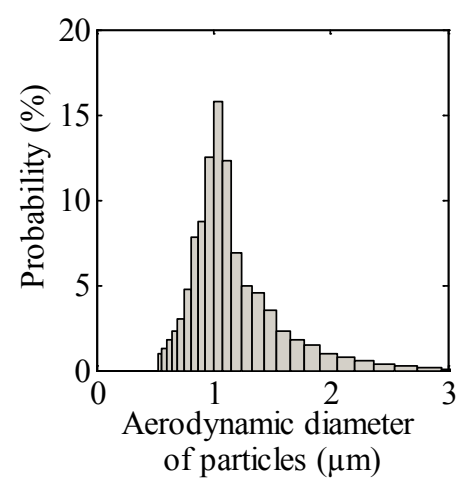

Figure 5. Characteristic size distribution of aerosol particles measured in the aerosol chamber, with the Aerodynamic Particle Sizer.

in this sample is not at least one order of magnitude lower than the mass concentration sampled in the drops that crossed the aerosol chamber ([fluoDrop]), the measurement is discarded, and the experimental device completely cleaned.

Furthermore, we retained only measurements in which the:

- fluorescein concentration in the drops is at least twice the fluorometer's detection limit $\left(1 \times 10^{-11} \mathrm{~g} \mathrm{~mL}^{-1}\right)$,

- relative humidity is below $90 \%$ in the aerosol chamber, to match the operating ranges of both the aerosol spectrometers,

- aerosol concentrations in the aerosol chamber deduced from filter sampling and from aerosol spectrometers agreed in a range of $50 \%$. (Discrepancies between those two measurements are a signature that aerosol particles are not composed of fluorescein.)

This selection reduced the amount of reliable data to 163 events. For those events, the remaining uncertainties are calculated by evaluating the errors due to each instrument.

The main source of uncertainty of the collection efficiency is associated with the precision of the fluorescein concentration measurement in the drops. These uncertainties range from about $20 \%$ for most of the measurements, but they reach up to $45 \%$ for $0.6 \mu \mathrm{m}$ aerosol particles.

\section{Results and discussion}

Experiments are carried out for two drop sizes $\left(D_{\mathrm{d}}=2 \mathrm{~mm}\right.$ and $D_{\mathrm{d}}=2.6 \mathrm{~mm}$ ) and aerosol particles from $300 \mathrm{~nm}$ to $3.5 \mu \mathrm{m}$. All these measurements are performed in air at a temperature of $21 \pm 3^{\circ} \mathrm{C}$ and for a relative humidity between 23 and $80 \%$. Figure 6 presents all the collection efficiencies calculated from measurements, with the associated experimental uncertainties evaluated with the propagation of the uncertainty of each term of Eq. (5).

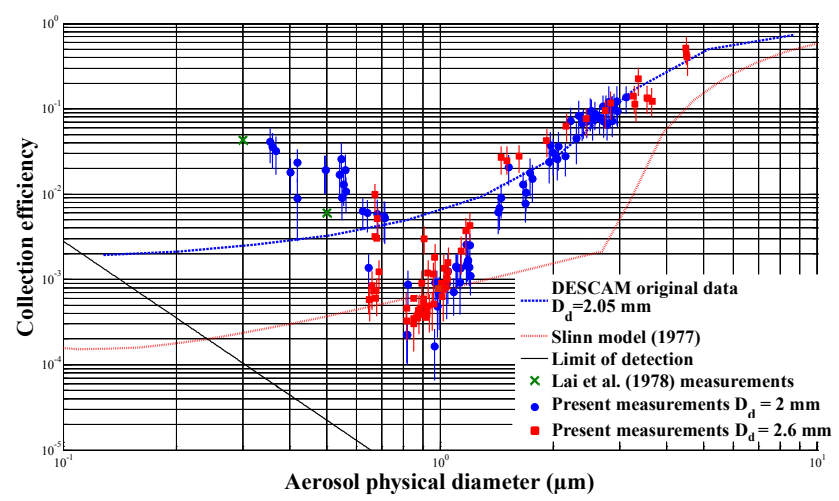

Figure 6. Collection efficiencies measured in the BERGAME experiment for 2 and $2.6 \mathrm{~mm}$ drop diameter as a function of particle diameter.

In Eq. (1), collection efficiencies are given as a function of drop size, aerosol particle size and relative humidity. This section will discuss the results and their dependence to these three parameters.

In the raindrop size range considered in this paper, no major influence of the drop diameter on the collection efficiencies is identified. The measurements obtained for drop diameters of 2 and $2.6 \mathrm{~mm}$ are almost identical.

For aerosol particle diameter between 0.3 and $3 \mu \mathrm{m}$, the collection efficiency varies a lot with aerosol particle size. The collection efficiency curve has a V-shape, in double logarithmic scale, with a minimum for an aerosol diameter close to $0.85 \mu \mathrm{m}$. As stated in the introduction this minimum is called the Greenfield gap. The measurements for the particles with a diameter smaller than $0.85 \mu \mathrm{m}$ (left branch of the Vshaped curve) are compared to the only measurements found in the literature (Lai et al., 1978). These results are close to present measurements (Fig. 6). The increased collection efficiency observed for aerosol particles larger than $0.85 \mu \mathrm{m}$ can be attributed to impaction mechanisms on the "leading edge" of the raindrop. The increase in aerosol inertia with increasing size no longer allows them to follow the streamline around the drop.

In order to test the validity of the Slinn model, it is compared to the present measurements. Figure 7 highlights that this model underestimates the collection efficiency by at least one order of magnitude. This difference might be attributed to difficulties in correctly modelling the fall of supermillimetric raindrops. In fact, $2 \mathrm{~mm}$ drops at terminal velocities are slightly oblate (see Fig. 3) and thus offer a greater cross section to the flow. However, the Slinn model was developed for spherical drops:

$$
\begin{aligned}
& E_{\mathrm{imp}}=\left[\frac{S t-S t^{*}}{\frac{2}{3}+S t-S t^{*}}\right]^{3 / 2}, \\
& \text { with } S t^{*}=\frac{1.2+1 / 12 \ln (1+R e)}{1+\ln (1+R e)}, \text { and } S t=\frac{2 V_{\mathrm{d}} \tau}{D_{\mathrm{d}}},
\end{aligned}
$$




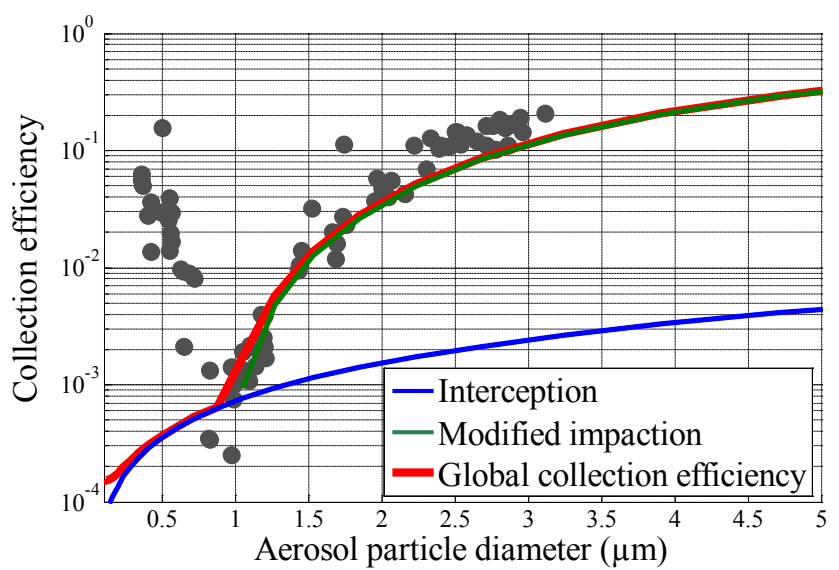

Figure 7. Different parameterisations of the Slinn (1977) model for impaction scavenging; blue curve: classical Slinn model for interception; green curve: modified Slinn model for impaction (Eq. 7); red curve: global inertial contributions to collection efficiency.

where $\tau$ is the relaxation time of the particle; it is the time needed for a particle to reach $\frac{1}{e^{1}}$ of its terminal velocity in a gravitational field and exposed to the drag forces $(\tau=$ $\frac{\rho_{\mathrm{d}} \rho_{\mathrm{ap}}^{2} C_{\mathrm{c}}}{18 \mu_{\mathrm{g}}}$, where $\rho_{\mathrm{d}}$ is the particle density, $d_{\mathrm{ap}}$ is the particle diameter and $\mu_{\mathrm{g}}$ is the gas dynamic viscosity).

For this particular data set, an empirical correction of the Slinn impaction term (Eq. 7) is proposed to better fit these measurements (green curve in Fig. 7):

$E_{\mathrm{imp}}=\left[\frac{0.2+S t-S t^{*}}{\frac{2}{3}+S t-S t^{*}}\right]^{3 / 2}$

This correction depends on the drop collection cross section, in other words the drop axis ratio. If other experiments are performed in BERGAME, it would be interesting to relate this correction to drop axis ratio.

The increase in collection efficiency for aerosol diameters smaller than $0.85 \mu \mathrm{m}$ is less evident. Neither the Slinn model nor DESCAM represent this sharp increase in collection efficiency. This leads to an underestimation of the collection efficiency, for $0.3 \mu \mathrm{m}$ particles, of one order of magnitude for the DESCAM model and two orders of magnitude for the Slinn model. In DESCAM the collection efficiencies are a compilation of measurements from publications without observations in that drop size range. For a discussion on how this underestimation can impact the total mass of aerosol particles washed out by rain, see Quérel et al. (2014).

Concerning the Slinn model, it lacks the increase because the hypothesis of potential flow is not valid, especially in the wake of the drop, where recirculating eddies seem to develop at Reynolds numbers larger than 20 (a drop of $280 \mu \mathrm{m}$ diameter falling at terminal velocity has a Reynolds numbers of 20). Beard (1974) calculated the influence of these eddies on the collection efficiencies. He found that the smallest aerosol particles are trapped by the vortices on the trailing side of the drop, which induce rear capture of these aerosols. A linear extrapolation of Beard (1974) calculations to our drop size is presented in Fig. 8. With regard to our experimental Reynolds numbers (Table 1), this extrapolation might seem daring because, in his theoretical study, Beard (1974) predicted that eddy shedding should start at Reynolds numbers close to 450 , leading to a decrease in aerosol particle collection efficiency in the submicron range. Nevertheless, this extrapolation is in line with our measurements in the submicron range. However, Beard (1974) proposed this transition for perfectly spherical drops, and the experiments highlight that $2 \mathrm{~mm}$ drops falling at terminal velocity are slightly oblate (Fig. 3), and moreover oscillate at high frequencies (Szakáll et al., 2009, 2010). As a consequence, it can be expected from current experiments that eddy shedding should start only at Reynolds numbers greater than 800 . This expectation is confirmed by flow characterisations performed by Quérel (2012) with the help of PIV techniques (Adrian, 1986; see also Quérel et al., 2014; Fig. 4). These measurements highlight that at a Reynolds number of 800 the vortices behind the drop could be still be stuck to the drop. In order to validate the mechanism of rear capture predicted by Beard (1974), it is planned to perform measurements of the collection efficiency of $1 \mathrm{~mm}$ raindrops, and thus a direct comparison with Bear calculations could be performed without any extrapolation.

From this measurement, no manifest influence of the relative humidity is noticed, for $2 \mathrm{~mm}$ drops (Fig. 9). Indeed, according to the experimental uncertainties presented in Fig. 6, Fig. 9 shows no significant effect of the relative humidity on the collection efficiency. In order to understand this result, a comparison of this measurement with the semi-empirical correlation introduced by Davenport and Peters (1978) to calculate the elementary collection efficiency due to diffusiophoresis (Eq. 8), was performed and is presented in Fig. 9:

$$
\begin{gathered}
E_{\mathrm{dph}}=\frac{4 T_{\mathrm{air}} D_{\mathrm{w} \rightarrow \mathrm{air}}}{P V_{\mathrm{d}} D_{\mathrm{d}}}\left(2+0.6 R e^{1 / 2} S c^{1 / 3}\right) \\
\left(\frac{P_{\mathrm{sat}, \mathrm{air}}}{T_{\mathrm{d}}}-\frac{P_{\mathrm{sat}, \mathrm{air}} \mathrm{RH}}{T_{\mathrm{air}}}\right) \sqrt{\frac{M_{\mathrm{w}}}{M_{\mathrm{air}}}},
\end{gathered}
$$

where $P_{\text {sat,air }}$ is the water vapour saturation pressure $(\mathrm{Pa})$, $D_{\mathrm{w} \rightarrow \text { air }}$ is the diffusion coefficient of water vapour in air $\left(\mathrm{m}^{2} \mathrm{~s}^{-1}\right), M_{\mathrm{w}}$ and $M_{\text {air }}$ are respectively the molar masses of water and air $\left(\mathrm{kg} \mathrm{mol}^{-1}\right), P$ the atmosphere pressure $(\mathrm{Pa})$, and finally $T_{\mathrm{d}}$ and $T_{\text {air }}$ are the respective temperatures of the drop and the air $(\mathrm{K})$. Current measurements do not reveal any major inconsistency with that correlation. Indeed, for larger aerosol particles (diameter greater than $1.5 \mu \mathrm{m}$ ) the collection efficiencies measured are at least one order of magnitude greater than the diffusiophoretic elementary collection efficiency of Eq. (8). Thus, in that aerosol particle size range, the aerosol collection is totally driven by inertial impaction, and no contribution of phoretic forces should be observed. Below 


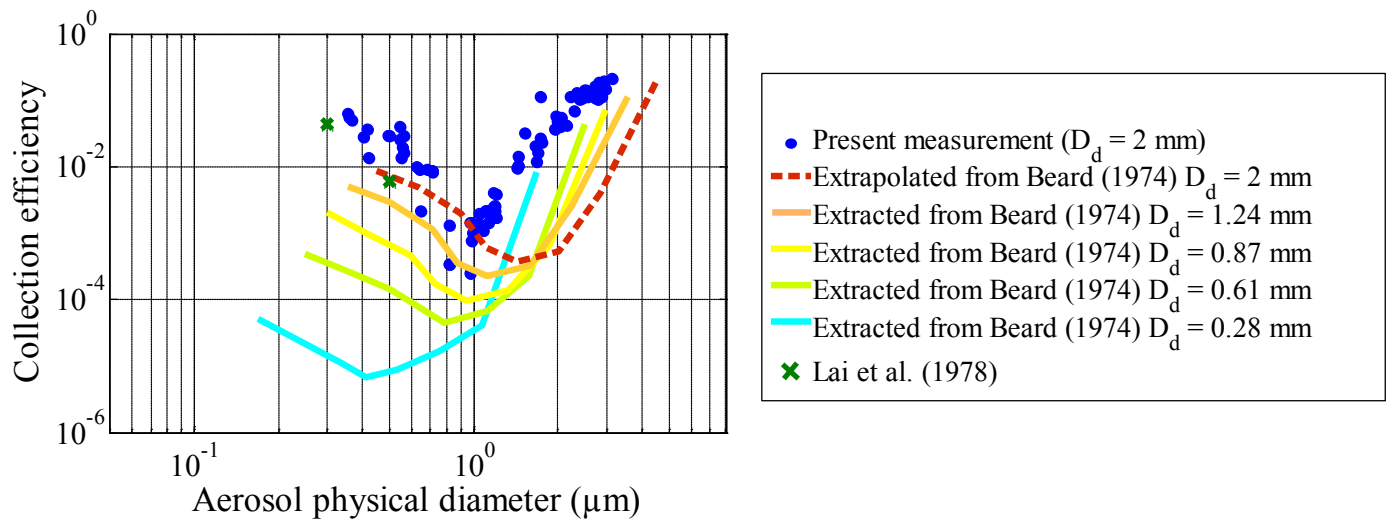

Figure 8. Comparison of present experimental results (blue dots) to the Beard (1974) rear capture model; solid and dashed curves are respectively extracted and extrapolated from Beard (1974).

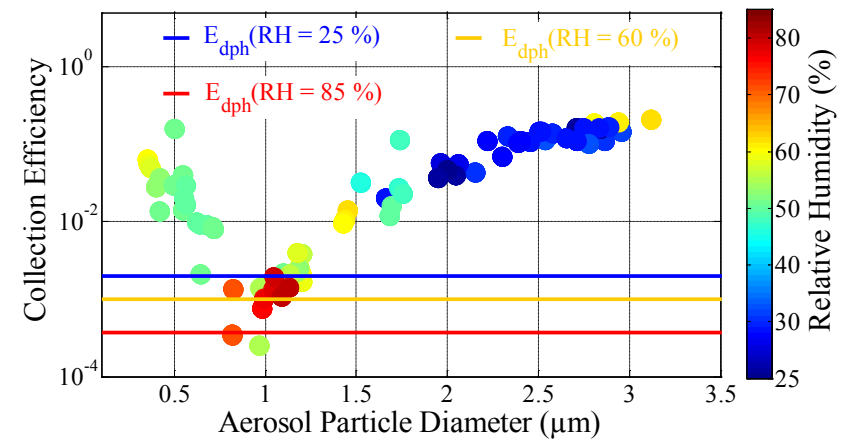

Figure 9. Collection efficiencies measured for drops of $2 \mathrm{~mm}$ in diameter as a function of relative humidity, and comparison with the model of Davenport and Peters (1978), a semi-empirical correlation to evaluate diffusiophoretic elementary collection efficiency.

$0.5 \mu \mathrm{m}$, it is observed that the collection efficiencies measured are still one order of magnitude greater than the diffusiophoretic elementary collection efficiency. The Davenport and Peters (1978) equation is, thus, consistent with the measurements presented for both these size ranges.

It seems that, close to the minimum in efficiency (between 0.6 and $1.2 \mu \mathrm{m}$ ), diffusiophoretic effects are overestimated by the Davenport and Peters (1978) equation. To confirm this observation, it would have been very interesting to make measurements in that aerosol particle size range but with low relative humidity (close to $20 \%$ ). Unfortunately, this was not possible in the current study.

\section{Conclusions}

This study provides 163 measurements of the collection efficiency with raindrop and particle sizes controlled and measured. These measurements have been performed for drop sizes of 2 and $2.6 \mathrm{~mm}$. This size range for drops was selected for different reasons. First, the DESCAM model highlighted that this size range is the one that collects the most particle mass, and thus is the most important in terms of ground contamination in the case of potential severe accident, e.g. in a nuclear installation resulting in radiological release. Second, in this drop size range available publications offer almost no measurements. Third, the collection efficiencies for millimetric raindrops are particularly difficult to calculate analytically because such large drops at terminal velocity oscillate and leave turbulence in their wake. Thus, a new facility called BERGAME was designed, built and used to experimentally determine collection efficiencies for these drop size ranges.

These measurements were initially compared to the few measurements given in the publications in that drop size range. The Lai et al. (1978) measurements correlate perfectly with ours; however, for $2 \mathrm{~mm}$ drops, they only performed two collection efficiency measurements: for aerosol particle diameters of 0.3 and $0.5 \mu \mathrm{m}$. As a consequence, Lai et al. (1978) did not cover the minimum collection efficiency that our measurements revealed close to $0.85 \mu \mathrm{m}$.

The Slinn model is also unable to predict this sharp increase in collection efficiency. It underestimates the efficiencies for $0.3 \mu \mathrm{m}$ particles by two orders of magnitude. In fact, the hypothesis of potential flow used in the Slinn model is not correct, especially in the wake of the drops, since recirculating eddies develop on the downstream side.

Beard (1974) calculated that these vortices induce rear capture and thus lead to the sharp increase in collection efficiency in the submicron range. The extrapolation of Beard (1974) simulations to $2 \mathrm{~mm}$ drops matches the current measurements perfectly. It thus seems that rear capture of submicron aerosol particles explains this sharp increase in collection efficiency.

In the micron range, the global shape of the Slinn model is in accordance with our measurements; however, it significantly underestimates collection efficiencies. This difference is attributable to the oblate shape of the raindrop that increases its cross section. A correction to the parameterisation 
of the Slinn model is proposed for $2 \mathrm{~mm}$ raindrops in order to fit the exponential results. It would be interesting to propose a more universal and robust parameterisation of this model. This would be possible with collection efficiencies measured for additional raindrop sizes. We could check whether the increase in collection efficiency, compared to the Slinn model outputs, could be linked to the increase in the hydrometeor cross section due to deformation.

Regarding current measurements, the initial collection efficiency of the DESCAM model is updated, giving some significant changes in the below-cloud scavenging modelling (Quérel, 2012; Quérel et al., 2014). However, as was also concluded in these publications, only drops with diameter between 2 and $2.6 \mathrm{~mm}$ have been measured in the BERGAME experiment, and other drop sizes have yet to be measured.

In addition, the range of aerosol particles sizes measured is not complete. It would be interesting to extend the collection efficiency measurements to the entire range of the accumulation mode $(0.1$ to $1 \mu \mathrm{m})$, with the intention to further improve the below-cloud scavenging modelling. These measurements would be performed with another technique, in order to enhance the limit of detection (e.g. atomic spectroscopy).

In the same way, the range of relative humidity has to be extended, even though measurements in the aerosol chamber become very difficult for relative humidity greater than $90 \%$. Above this, the influence of the hygroscopicity of the particles used here is not known.

Other experimental parameters are not explicitly explored in this first approach. Indeed, the influence of electric charges on particle collection is known (e.g. Pranesha and Kamra, 1996), so all experimental efforts were made to keep these effects to a minimum in this study. At a later date, however, it will be necessary to explore this parameter in the collection efficiencies of aerosol particles by $2 \mathrm{~mm}$ drops.

Finally, from a longer-term point of view, if all these recommended experiments on the collection of particles by raindrops are conducted, it will be necessary to apply the same kind of thorough study on collection for the other hydrometeors (snow, hail, etc.) in order to improve our knowledge of below-cloud scavenging, and upgrade the modelling process.

Edited by: P. Herckes

\section{References}

Adrian, R. J.: Multi-point optical measurements of simultaneous vectors in unsteady flow-a review, Int. J. Heat Fluid Fl., 7, 127145, 1986.

Baklanov, A. and Sørensen, J. H.: Parameterisation of radionuclide deposition in atmospheric long-range transport modelling, Phys. Chem. Earth B, 26, 787-799, 2001.

Baron, P. A. and Willeke, K.: Aerosol Measurement, Principles, Techniques, and Applicaions (New York/Chichester/Weinheim/Brisbane/Singapore/Toronto), 2001.
Beard, K. V.: Experimental and numerical collision efficiencies for submicron particles scavenged by raindrops, J. Atmos. Sci., 31, 1595-1603, 1974.

Beard, K. V.: Terminal velocity and shape of cloud and precipitation drops aloft, J. Atmos. Sci., 33, 851-864, 1976.

Beard, K. V. and Chuang, C.: A new model for the equilibrium shape of raindrops, J. Atmos. Sci., 44, 1509-1524, 1987.

Bemer, D. and Tierce, P.: Ultrasonic generation of droplets for the production of fluorescein aerosol of mass median aerodynamic diameter between 1 and $10 \mu \mathrm{m}$ and geometric standard deviation $<1.5$, J. Aerosol Sci., 27, 393-394, 1996.

Bringi, V. N., Chandrasekar, V., Hubbert, J., Gorgucci, E., Randeu, W. L., and Schoenhuber, M.: Raindrop size distribution in different climatic regimes from disdrometer and dual-polarized radar analysis, J. Atmos. Sci., 60, 354-365, 2003.

Davenport, H. M. and Peters, L. K.: Field studies of atmospheric particulate concentration changes during precipitation, Atmos. Environ., 12, 997-1008, 1978.

Flossmann, A. I.: A theoretical investigation of the removal of atmospheric trace constituents by means of a dynamic model, $\mathrm{PhD}$ thesis, university Johannes Gutenberg, Mainz, 1986.

Flossmann, A. I.: The scavenging of two different types of marine aerosol particles calculated using a two-dimensional detailed cloud model, Tellus B, 43, 301-321, 1991.

Flossmann, A. I.: Interaction of aerosol particles and clouds, J. Atmos. Sci., 55, 879-887, 1998.

Flossmann, A. I. and Wobrock, W.: A review of our understanding of the aerosol-cloud interaction from the perspective of a bin resolved cloud scale modelling, Atmos. Res., 97, 478-497, 2010.

Greenfield, S. M.: Rain scavenging of radioactive particulate matter from the atmosphere, J. Meteorol., 14, 115-125, 1957.

Grover, S. N., Pruppacher, H. R., and Hamielec, A. E.: A numerical determination of the efficiency with which spherical aerosol particles collide with spherical water drops due to inertial impaction and phoretic and electrical forces, J. Atmos. Sci., 34, 1655-1663, 1977.

Hinds, W. C.: Aerosol technology, Wiley-Interscience, New York, 1982.

Hobbs, P. V.: Aerosol-Cloud-Climate Interactions (San Diego/New York/Boston/London/Sydney/Tokyo/Toronto), 1993.

Jaenicke, R.: Aerosol physics and chemistry, in: LandoltBoernstein: Zahlenwerte und Funktionen aus Naturwissenschaften und Tecknik, edited by: Fischer, G., 4b, 391-457, 1988.

Kerker, M. and Hampl, V.: Scavenging of aerosol particles by a falling water drops and calculation of washout coefficients, J. Atmos. Sci., 31, 1368-1376, 1974.

Laakso, L., Grönholm, T., Rannik, Ü., Kosmale, M., Fiedler, V., Vehkamäki, H., and Kulmala, M.: Ultrafine particle scavenging coefficients calculated from 6 years field measurements, Atmos. Environ., 37, 3605-3613, 2003.

Lai, K.-Y., Dayan, N., and Kerker, M.: Scavenging of aerosol particles by a falling water drop, J. Atmos. Sci., 35, 674-682, 1978.

Marjamaki, M., Keskinen, J., Chen, D. R., and Pui, D. Y. H.: Performance evaluation of the electrical low-pressure impactor (ELPI), J. Aerosol Sci., 31, 249-261, 2000.

Marshall, J. S. and Palmer, W. M.: The distribution of raindrops with size, J. Meteorol., 5, 165-166, 1948. 
Mocho, V.: Pollution microbienne, particulaire et gazeuse d'un espace protégé par une ou plusieurs barrières de confinement dynamique, PhD thesis, University of Paris-Val-de-Marne, Paris XII, 1996.

Motzkus, C.: Etude de la mise en suspension de particules lors de l'impact de gouttes, PhD thesis, Paris XII, 2007.

Pranesha, T. S. and Kamra, A. K.: Scavenging of aerosol particles by large water drops 1 . Neutral case, J. Geophys. Res., 101, 23373-23380, 1996.

Pruppacher, H. R. and Klett, J. D.: Microphysics of Clouds and Precipitation (Dordrecht/Boston/London), 1997.

Quérel, A.: Lessivage de l'atmosphère par la pluie?: approche microphysique, $\mathrm{PhD}$ thesis, University Blaise Pascal, ClermontFerrand, 2012.

Quérel, A., Monier, M., Flossmann, A. I., Lemaitre, P., and Porcheron, E.: The importance of new collection efficiency values including the effect of rear capture for the belowcloud scavenging of aerosol particles, Atmos. Res., 142, 57-66, doi:10.1016/j.atmosres.2013.06.008, 2014.

Skibin, D., Kaimal, J. C., and Gaynor, J. E.: Could the vertical velocity explain the discrepancy between theory and measurements of air polution?, in: 7th Symp. on Turbulence and Diffusion, (Boston, U.S.A.), 1986.

Slinn, W. G. N.: Some approximations for the wet and dry removal of particles and gases from the atmosphere, Water Air Soil Poll., 7, 513-543, 1977.

Szakáll, M., Diehl, K., Mitra, S. K., and Borrmann, S.: A Wind Tunnel Study on the Shape, Oscillation, and Internal Circulation of Large Raindrops with Sizes between 2.5 and $7.5 \mathrm{~mm}$, J. Atmos. Sci., 66, 755-765, 2009.
Szakáll, M., Mitra, S. K., Diehl, K., and Borrmann, S.: Shapes and oscillations of falling raindrops - A review, Atmos. Res., 97, 416-425, 2010.

Thurai, M., Bringi, V. N., Szakáll, M., Mitra, S. K., Beard, K. V., and Borrmann, S.: Drop Shapes and Axis Ratio Distributions: Comparison between 2D Video Disdrometer and Wind-Tunnel Measurements, J. Atmos. Ocean. Tech., 26, 1427-1432, 2009.

Villani, P., Picard, D., Michaud, V., Laj, P., and Wiedensohler, A.: Design and Validation of a Volatility Hygroscopic Tandem Differential Mobility Analyzer (VH-TDMA) to Characterize the Relationships Between the Thermal and Hygroscopic Properties of Atmospheric Aerosol Particles, Aerosol Sci. Tech., 42, 729-741, 2008.

Vohl, O., Wurzler, S., Diehl, K., Huber, G., Mitra, S. K., and Pruppacher, H. R.: Experimental and theoritical studies of the effects of turbulence on impaction scavenging of aerosols, gas uptake by water drops, and collisional drop growth, J. Aerosol Sci., 30, S575-S576, 1999.

Volken, M. and Schumann, T.: A critical review of below-cloud aerosol scavenging results on Mt Rigi, Water Air Soil Poll., 68, 15-28, 1993.

Wang, P. K. and Pruppacher, H. R.: An experimental determination of the efficiency with which aerosol particles are collected by water drops in subsaturated air, J. Atmos. Sci., 34, 1664-1669, 1977.

Wang, P. K., Grover, S. N., and Pruppacher, H. R.: On the effect of electrical charges on the scavenging of aerosol particles by clouds and small raindrops, J. Atmos. Sci., 35, 1735-1743, 1978.

Whitby, K. T.: On the multimodal nature of atmospheric size distribution, 3rd int. Conf. on Nucleation, Leningrad, USSR, 1973. 